\title{
Amine functionalized cubic mesoporous silica nanoparticles as an oral delivery system for curcumin bioavailability enhancement
}

\author{
Sandy Budi Hartono ${ }^{1,4}$, Lannie Hadisoewignyo ${ }^{2}$, Yanan Yang $^{3}$, \\ Anand Kumar Meka ${ }^{3}$, Antaresti ${ }^{1}$ and Chengzhong $\mathrm{Yu}^{3,4}$ \\ ${ }^{1}$ Department of Chemical Engineering, Widya Mandala Catholic University, Surabaya, Indonesia \\ ${ }^{2}$ Faculty of Pharmacy, Widya Mandala Catholic University, Surabaya, Indonesia \\ ${ }^{3}$ Australian Institute for Bioengineering and Nanotechnology, The University of Queensland, Brisbane, \\ QLD 4072, Australia
}

E-mail: sandy@ukwms.ac.id and c.yu@uq.edu.au

Received 1 August 2016, revised 29 October 2016

Accepted for publication 31 October 2016

Published 22 November 2016

\begin{abstract}
In the present work, a simple method was used to develop composite curcumin-amine functionalized mesoporous silica nanoparticles (MSN). The nanoparticles were used to improve the bioavailability of curcumin in mice through oral administration. We investigated the effect of particle size on the release profile, solubility and oral bioavailability of curcumin in mice, including amine functionalized mesoporous silica micron-sized-particles (MSM) and MSN (100-200 nm). Curcumin loaded within amine functionalized MSN (MSN-A-Cur) had a better release profile and a higher solubility compared to amine MSM (MSM-A-Cur). The bioavailability of MSN-A-Cur and MSM-A-Cur was considerably higher than that of 'free curcumin'. These results indicate promising features of amine functionalized MSN as a carrier to deliver low solubility drugs with improved bioavailability via the oral route.
\end{abstract}

Keywords: mesoporous silica nanoparticles, oral delivery platform, curcumin

(Some figures may appear in colour only in the online journal)

\section{Background}

Curcumin is an active agent that can be found from rhizomes of the Curcuma longa plant. This active agent has a high potency to treat various diseases (e.g. diabetes, cancer, allergies, arthritis and Alzheimer's disease) mainly due to its anti-oxidant, anti-inflammation and anti-viral properties [1]. Nevertheless, these benefits are hampered by the low bioavailability of curcumin because it has a negligible solubility in water and only limited solubility in ethanol or acetone [1-3]. The construction of curcumin nanoparticles and nano-formulations is an effective way to increase its bioavailability, including the use of liposomes, micelles, phospholipid

${ }^{4}$ Author to whom any correspondence should be addressed. complexes and curcumin analogs [1]. However, these organic-based formulations have stability issues. Curcumin analog has similar properties to its predecessor, but its safety profile has not been clearly demonstrated and requires further studies [2].

Over the past decade, mesoporous silica (MS) materials have been used extensively in many investigations to improve the efficacy of drug and gene delivery [4-12]. MS materials have shown promising potential as oral drug or parenteral drug carriers [13]. Taking the advantages of their very high surface area and pore volume, MS materials are capable of carrying a large quantity of cargos for various applications, including catalysis, chemical synthesis, enzyme immobilization and drug delivery. Previous research showed the use of MS to increase the solubility of various insoluble drugs such 
as doxorubicin and paclitaxel [10, 14]. Different strategies have also been reported to produce curcumin-mesoporous silica nanocomposites, including the formation of guanidine functionalized PEGylated mesoporous silica nanoparticles (MSN) [15], lipid bilayer-coated curcumin-based MSN [16], curcumin-loaded silica encapsulated porous chitosan [17], mesoporous silica coated curcumin-lipid core [18], curcuminsilica composites with double functionalization [19] and composite hydrogels of chitosan-MSN [20].

These drug delivery systems are generated from complex synthesis and functionalization processes, limiting their practical applications due to the time consuming, rigorous procedures and high cost of production. A simple method that can produce multifunction carriers for effective drug delivery is in needed.

Studies have shown that the physicochemical properties of MS, including pore size, particle size, pore structure and surface functionalization affect the release profile of loaded molecules, which in turn influence the solubility [10, 19, 2123]. Careful optimization of these parameters can be a facile way to improve the bioavailability of various low solubility drugs. Previous reports on drug molecule-silica nanocomposites mostly focused on either mesoporous silica micronsized-particles (MSM) or MSN with small pore size $(<3 \mathrm{~nm})$ $[10,19,21-23]$. Small pores induce stronger steric hindrance to the adsorbed molecules compared to large pores. Further increasing the drug loading causes 'congestion' and limits the molecule diffusion in the nanopores, causing pore blocking, low loading and incomplete release of cargo molecules $[10,23]$.

To overcome the limitations, here we report amine functionalized cubic mesostructured MSN with 3D interconnected large pore size $(10 \mathrm{~nm})$ as carriers to improve curcumin bioavailabiliy in vivo. Comparing with the $2 \mathrm{D}$ pore system, the $3 \mathrm{D}$ pore system has a better mass transfer and more resistance to pore blockage [24]. Surface functionality is another important parameter of drug carriers [25-27] and amine functionalization onto silica materials has been proved to be an effective strategy in creating a controlled release profile for various molecules [28, 29]. In addition, Mitra et al showed that the interaction between primary amine of chitosan and phenolic group of curcumin via hydrogen bonding improved curcumin binding and stability [30]. The effect of particle size on curcumin release, solubility and bioavailability is also investigated. To the best of our knowledge, this is the first report using large-pore cubic mesostructured MSN for improving in vivo curcumin bioavailability through oral administration.

\section{Materials and methods}

\subsection{Chemicals}

Triblock poly(ethylene oxide)-b-poly(propylene oxide)-bpoly(ethylene oxide) copolymer $\mathrm{EO}_{106} \mathrm{PO}_{70} \mathrm{EO}_{106}$ (Pluronic F127, MW = 12 600), tetraethoxysilane (TEOS, 99\%), 1,3,5trimethylbenzene (TMB), 3-aminopropyltriethoxysilane
(APTES, 99\%), potassium chloride $(\mathrm{KCl})$, phosphate buffer tablets and Tween 80 were purchased from Aldrich. A fluorocarbon surfactant (FC-4) was purchased from Yick-Vic Chemicals \& Pharmaceuticals (HK) Ltd. All chemicals were used as received without purification.

\subsection{Synthesis of MSM and MSN with a cubic mesostructure}

MSM with a cubic mesostructure were synthesized following the previous method by Fan et al with some modifications [31]. Typically, $1 \mathrm{~g}$ of $\mathrm{F} 127$ and $5 \mathrm{~g}$ of $\mathrm{KCl}$ were mixed in $60 \mathrm{ml}$ of $2 \mathrm{M} \mathrm{HCl}$ at $20^{\circ} \mathrm{C}$ (synthesis temperature) and stirred for $30 \mathrm{~min}$. Then, $1.6 \mathrm{~g}$ of TMB was added and stirring was continued for $6 \mathrm{~h} .4 \mathrm{~g}$ of TEOS was added under stirring, and the mixture was continuously stirred for $24 \mathrm{~h}$ at $20^{\circ} \mathrm{C}$. Then, the mixture solutions were transferred to an autoclave and heated at $130{ }^{\circ} \mathrm{C}$ for $24 \mathrm{~h}$. After hydrothermal treatment, the product was separated, washed and dried. The surfactant was removed by calcination at $550{ }^{\circ} \mathrm{C}$ for $6 \mathrm{~h}$.

MSN with nano-sizes and a cubic mesostructure were synthesized following the previous method by Ying et al with some modification [32]. $0.5 \mathrm{~g}$ of F127 and 1.4 of $\mathrm{FC}_{4}$ were mixed in the solutions of $60 \mathrm{ml}$ of $0.02 \mathrm{M} \mathrm{HCl}$ then $0.5 \mathrm{~g}$ of TMB was added. After the solution was stirred for $4 \mathrm{~h}$, TEOS was added into the solutions and was stirred for $24 \mathrm{~h}$ at $20^{\circ} \mathrm{C}$. The solutions were then moved to an autoclave and heated at $130{ }^{\circ} \mathrm{C}$ for $24 \mathrm{~h}$ of hydrothermal treatment. The product was separated, washed and dried. The surfactant was removed by calcination similar to MSM synthesis.

\subsection{APTES modification}

Amine functionalization was conducted via a grafting method. $0.6 \mathrm{~g}$ of mesoporous silica (MSM, MSN) was added into $30 \mathrm{ml}$ of toluene. The mixture was stirred and heated to $70{ }^{\circ} \mathrm{C} .1 .2 \mathrm{ml}$ of APTES was added into the mixture and the stirring was continued for $20 \mathrm{~h}$. The product was centrifuged and dried [27]. The products were denoted MSM-A and MSN-A.

\subsection{Curcumin loading, in vitro release and solubility test}

The curcumin loading, release and solubility test were performed based on a method reported by Jambhrunkar et al [8]. $200 \mathrm{mg}$ of MS (MSM-A, MSN-A) was mixed with $50 \mathrm{mg}$ of curcumin in a rotary evaporation flask. $20 \mathrm{ml}$ of ethanol was added and the mixture was sonicated for 2 min using a bath sonicator. Ethanol was evaporated slowly under vacuum at a temperature of $55^{\circ} \mathrm{C}$. Finally curcumin loaded MS was obtained (MSM-A-Cur, MSN-A-Cur). A dialysis bag method was used to determine in vitro release of MSM-A-Cur and MSN-A-Cur. $25 \mathrm{mg}$ of curcumin loaded silica particles were mixed with $5 \mathrm{ml}$ of release solution (phosphate buffered saline (PBS) buffer $+0.8 \%$ Tween 80 ). The mixture was added into the dialysis bag (Sigma Aldrich) with $14 \mathrm{kDa}$ molecular weight cutoff. The curcumin-silica loaded mix was immersed in $200 \mathrm{ml}$ release solution. Then $1.0 \mathrm{ml}$ of samples were collected at a certain interval time to be determined by concentration. The samples were analyzed using a UV-vis 
spectrophotometer at $432 \mathrm{~nm}$. For the solubility test, an excess of curcumin loaded MS was added into $2 \mathrm{ml}$ of water. The mixture was kept under stirring for $48 \mathrm{~h}$ at $37^{\circ} \mathrm{C}$. A supernatant was collected and checked with a UV-vis spectrophotometer at $432 \mathrm{~nm}$.

\subsection{Bioavailability test}

Bioavailability of free curcumin, MSM-A-Cur and MSN-ACur in mice was compared. Twenty-four male rats weighing $250 \pm 20 \mathrm{~g}$ were randomly divided into three treatment groups and given free curcumin, MSM-A-Cur and MSN-ACur suspensions. The rats were fasted for $24 \mathrm{~h}$ before the experiment. A dose of each formulation $\left(50 \mathrm{mg} \mathrm{kg}^{-1}\right.$, contains $10 \mathrm{mg}$ curcumin $/ \mathrm{kg}$ ) was given through oral administration. Subsequently, $300 \mu \mathrm{l}$ of blood sample was collected from the tail into EDTA tubes at indicated time intervals. Plasma samples were separated by centrifugation at $3000 \mathrm{rpm}$ for $15 \mathrm{~min}$. Curcumin pharmacokinetic parameters were determined by using high performance liquid chromatography. The mobile phase consisted of acetic acid 2\%: acetonitrile in a combination of 60:40. The mobile was pumped at a flow rate of $1 \mathrm{ml} \mathrm{min}^{-1}$ at room temperature. After injection of the sample into the HPLC, the UV detection wavelength was set at $428 \mathrm{~nm}$.

\subsection{Characterization}

Transmission electron microscopy (TEM) images were obtained by a JEOL 1010 electron microscope with an acceleration voltage $100 \mathrm{kV}$. Nitrogen sorption isotherms of the samples were obtained using a Quantachrome's Quadrasorb SI analyser at $77 \mathrm{~K}$. Before the measurements, the samples were degassed overnight at $110{ }^{\circ} \mathrm{C}$ in vacuum. The Brumauer-Emmett-Teller (BET) surface area was calculated using experimental points at a relative pressure $\left(\mathrm{P} / \mathrm{P}_{0}\right)$ of 0.05-0.25. The total pore volume was calculated from the $\mathrm{N}_{2}$ amount adsorbed at the highest $\mathrm{P} / \mathrm{P}_{0}\left(\mathrm{P} / \mathrm{P}_{0}=0.99\right)$. For cubic structures, the cavity pore size and entrance pore size are determined from the adsorption and desorption branches, respectively, by using Barrett-Joyner-Halenda (BJH) model. TGA/DSC 1 (Mettler-Toledo AG) was used for thermogravimetric analysis (TGA) at a heating rate of $2{ }^{\circ} \mathrm{C} \mathrm{min}{ }^{-1}$ under a nitrogen flow of $20 \mathrm{ml} \mathrm{min}^{-1}$. XRD patterns were collected on a German Bruker D8 Advanced x-ray Diffractometer with $\mathrm{Ni}$ filtered $\mathrm{Cu} \mathrm{K} \alpha$ radiation $(40 \mathrm{kV}, 30 \mathrm{~mA})$. Each sample was scanned with attenuated total reflectance Fourier transform infrared spectroscopy (ATR-FTIR). A total of 128 scans were conducted within $350-4000 \mathrm{~cm}^{-1}$.

\section{Results and discussion}

\subsection{Synthesis and characterization}

Mesoporous silica materials with a cubic mesostructure and two different particle sizes were synthesized. The TEM images (figure 1) indicate the ordered structures of MSM (A) and MSN (B). The MSN had a particle size around $100 \mathrm{~nm}$,

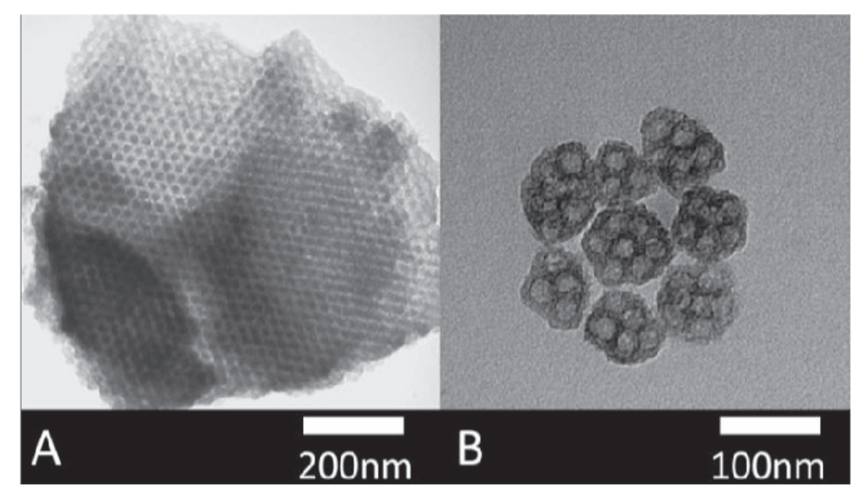

Figure 1. TEM images of (A) MSM and (B) MSN.

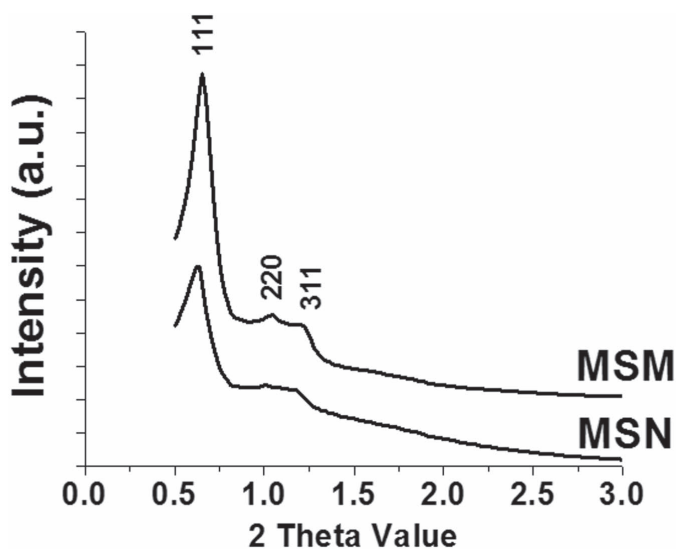

Figure 2. Powder XRD patterns of MSM and MSN.

while MSM showed micron-size particles with significantly larger size (around $1 \mu \mathrm{m}$ ). The typical interconnected pores can be seen from figure 1(A) [31].

The XRD patterns (figure 2) of MSM and MSN show similar peaks that can be indexed as 111, 220 and 311 reflections associated with a cubic symmetry $(F m \overline{3} m)$ [31]. Nitrogen sorption isotherms of MSM and MSN are presented in figure 3 showing a type- 2 hysteresis, which is typical of cubic mesostructures with large pores connected by entrances with smaller sizes. The pore size of both MSM and MSN were calculated to be $10 \mathrm{~nm}$.

Functionalization of porous silica materials was conducted by using a grafting method [27]. A total weight loss of $18 \%$ was observed after APTES functionalization of MSN based on TGA (figure 4), which is attributed to the grafting of amine moiety grafted on the surface of MSN. Successful amine functionalization is confirmed further from FTIR analysis (figure 5). The FTIR spectra of MSN, MSN-A and MSN-A-Cur showed similar peaks at $950 \mathrm{~cm}^{-1}$ (Si-OH) and $1100 \mathrm{~cm}^{-1}$ (Si-O-Si). The amine functionalized MSN (MSNA) exhibited a broad peak at around 2800 to $3300 \mathrm{~cm}^{-1}$ indexed to $\mathrm{N}-\mathrm{H}$ bending and stretching of primary amines and another peak at $1550 \mathrm{~cm}$ attributed to $\mathrm{N}-\mathrm{H}$ bending vibration [33].

The FTIR spectra of MSN-A-Cur had several peaks similar to free curcumin $(\Delta)$. These peaks were found at $3020 \mathrm{~cm}^{-1}\left(\mathrm{C}-\mathrm{H}\right.$ stretching of aromatic rings), $1650 \mathrm{~cm}^{-1}$ $(\mathrm{C}=\mathrm{O}$ stretching $), 1510 \mathrm{~cm}^{-1}(\mathrm{C}=\mathrm{O}$ and $\mathrm{C}=\mathrm{C}$ vibration $)$ and 

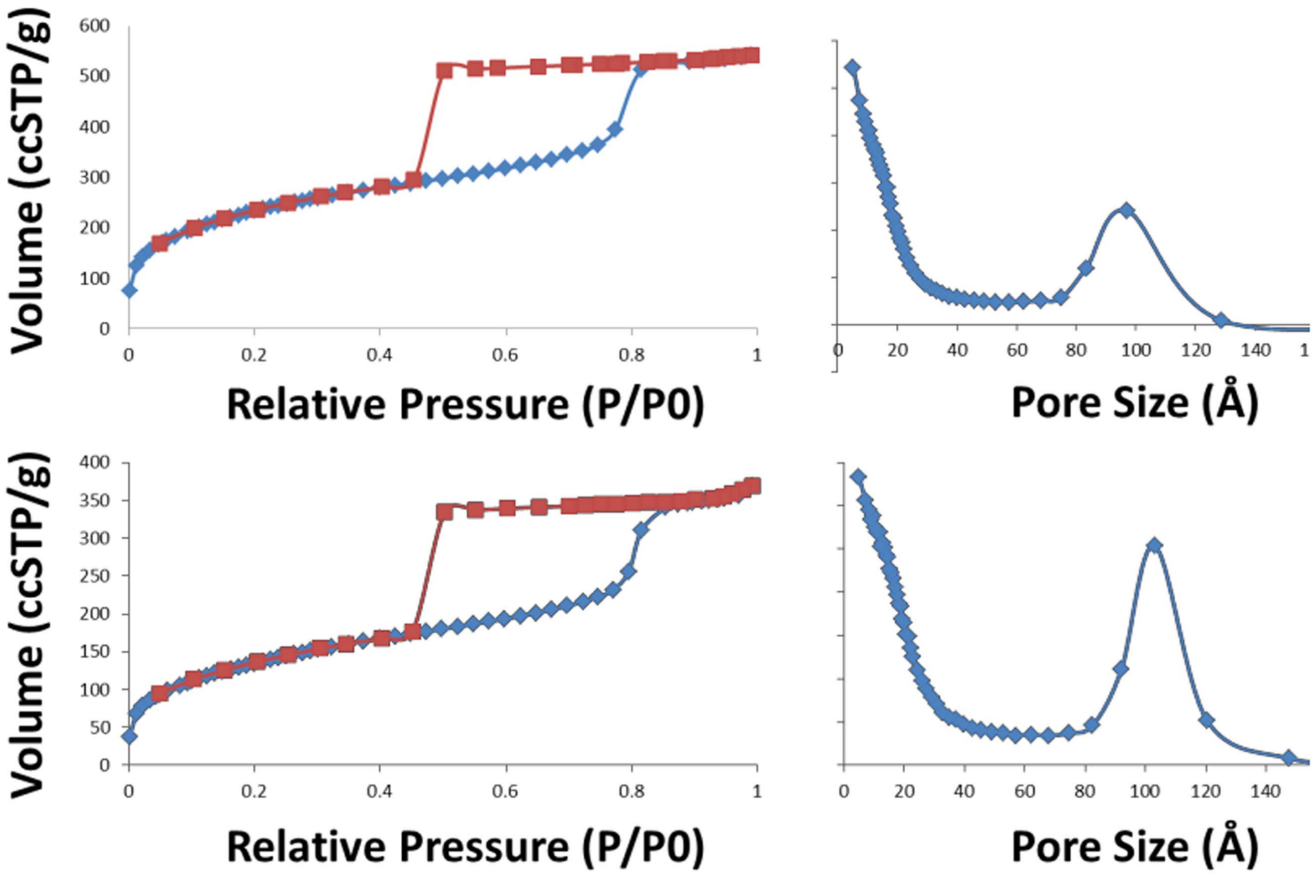

Figure 3. Nitrogen sorption and pore distribution of MSM and MSN.

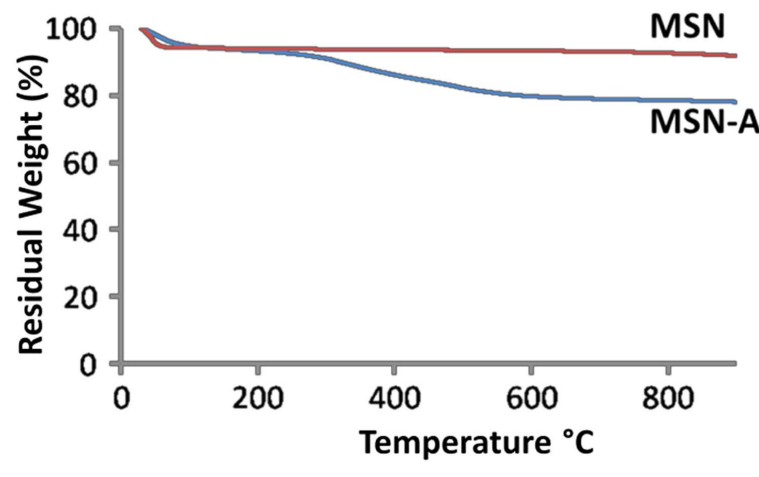

Figure 4. TGA profile of MSN and MSN-A.

$1300 \mathrm{~cm}^{-1}\left(\mathrm{CH}_{3}\right.$ bending) [8]. The spectra of MSN-A-Cur showed a new peak at $3100 \mathrm{~cm}^{-1}\left(^{*}\right)$, suggesting the formation of hydrogen bonding between amine groups of MSN-A and phenolic hydroxyl group of curcumin [30].

\subsection{In vitro release and solubility of curcumin}

Figure 6 shows the in vitro release profiles for free curcumin, MSM-A-Cur and MSN-A-Cur. The drug release in the free curcumin group reached a plateau at $\sim 5 \mathrm{~h}$ with an accumulated release amount of just $4 \%$. The amount of curcumin released to the media was higher in both MSM-A and MSN-A groups. Moreover, both silica groups showed a prolonged release profile with the release reaching a plateau after $48 \mathrm{~h}$. The curcumin released from MSN-A reached 12\%, higher than that in MSM-A group (9\%). The results clearly show that the use of amine functionalization MSN successfully regulates the curcumin release and creates a prolonged release.

The release amounts of MSN-A and MSM-A were higher compared to previously reported MS materials. It was reported that the curcumin release amount from amine functionalized MSU-2 with a pore size of $4.7 \mathrm{~nm}$ and amine functionalized MCM-41 with a pore size of $1.8 \mathrm{~nm}$ reached only $8.8 \%$ and $1.5 \%$, respectively [19]. It can be seen that pore size has influence on the release content of curcumin. Large pores and small particle sizes lead to a higher release amount of curcumin.

The solubility of curcumin in the three groups (free curcumin, MSM-A-Cur and MSN-A-Cur) is presented in figure 7 for a direct comparison. The solubility of curcumin in the MSN-A group was almost ten times higher than the free curcumin group and almost twice as high than the MSM-A group. The significant increase of curcumin solubility of MSN-A and MSM-A compared to free curcumin should be attributed to the decrease of curcumin particle size. It is generally known that reducing drug particle size enhances drug solubility [8, 34]. The particle sizes of curcumin encapsulated within nanopores of MSM- A and MSN-A were notably reduced compared to the free curcumin.

In addition, the MS particle size has influence on the effectiveness of mass diffusion. The nano-size particles (MSN-A) have similar structures to the micron-size particles (MSM-A). The reduced diffusion length alleviates the steric hindrance and accelerates particle release, which causes higher dissolution rate and finally increased curcumin solubility [13].

The in vivo bioavailability of free curcumin, MSN-A-Cur and MSM-A-Cur in mice was compared through oral delivery. Three groups of mice were given curcumin, MSN-A-Cur and MSM-A-Cur with the same curcumin dosage of $50 \mathrm{mg} \mathrm{kg}^{-1}$. Blood samples were collected to detect the curcumin content. During the analysis, the curcumin concentration in the free curcumin group was low at all time points (figure 8). In contrast, the curcumin concentration in the 

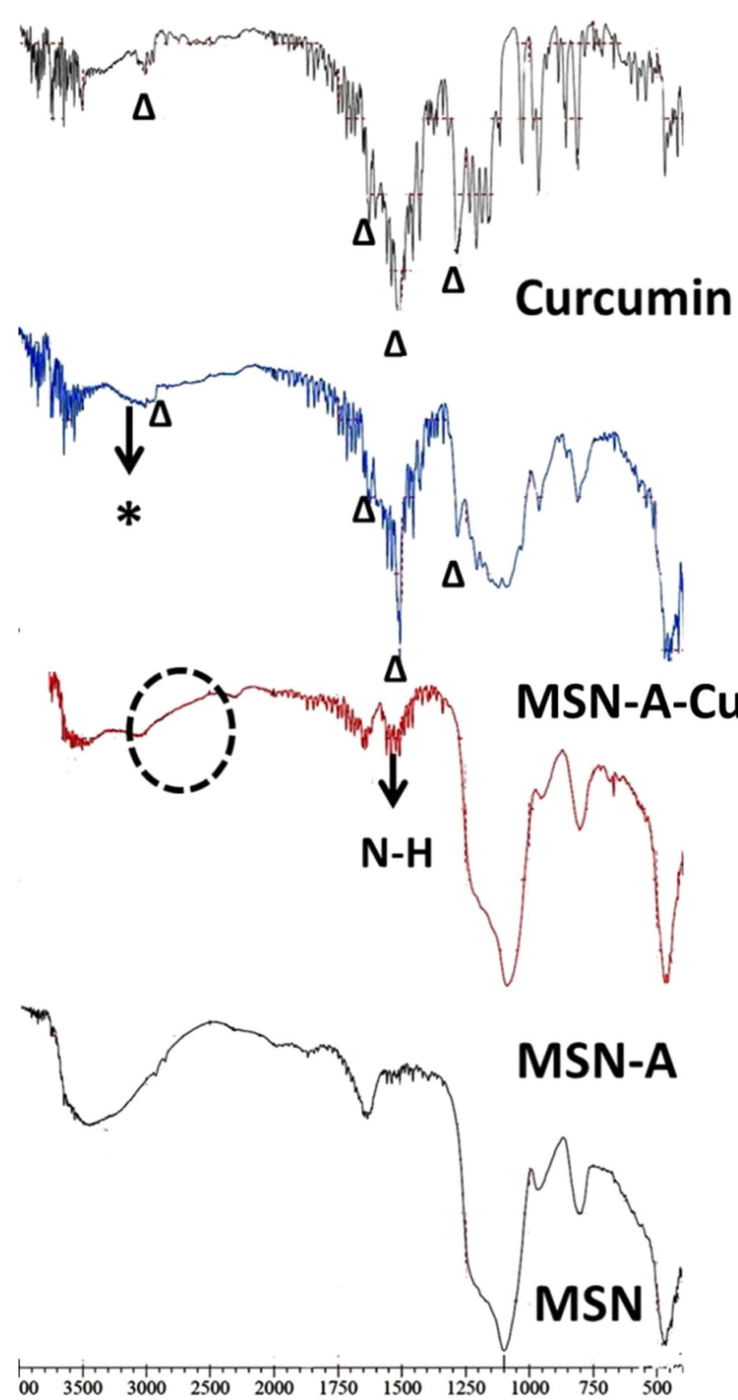

Figure 5. FTIR analysis of various samples.

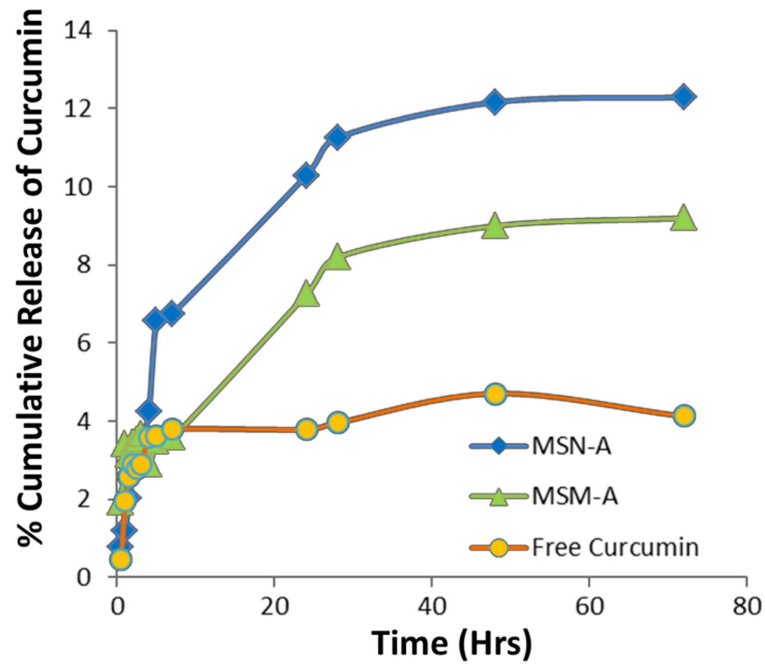

Figure 6. In vitro release profile of MSN-A-Cur, MSM-A-Cur and free curcumin.

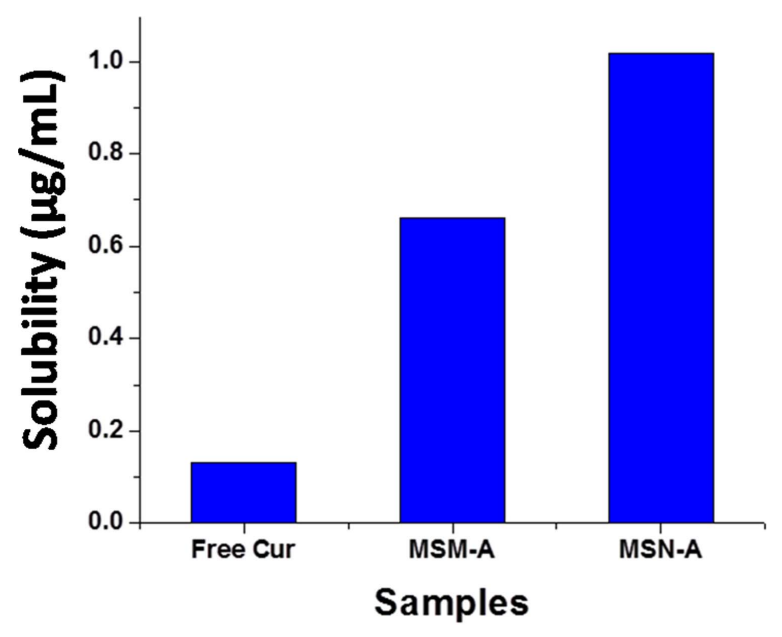

Figure 7. Aqueous solubility of MSN-A-Cur, MSM-A-Cur and free curcumin.

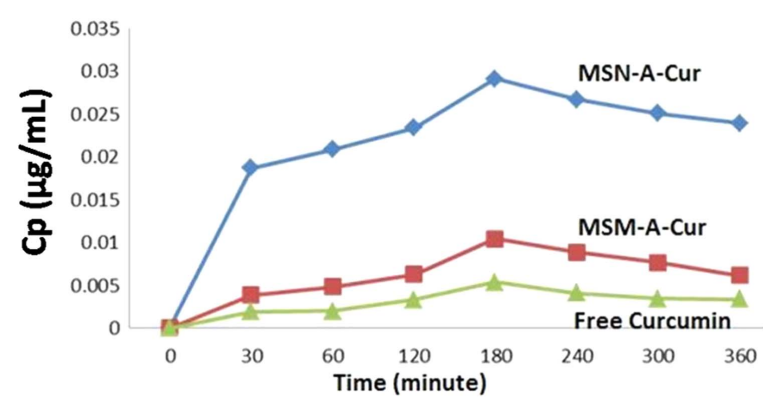

Figure 8. Bioavailability test of MSN-A-Cur, MSM-A-Cur and free curcumin.

Table 1. Pharmacokinetic parameters of MSN-A and MSM-A in mice plasma.

\begin{tabular}{lcc}
\hline & \multicolumn{2}{c}{ Samples } \\
\cline { 2 - 3 } $\begin{array}{l}\text { Pharmacokinetic } \\
\text { parameters }\end{array}$ & $\begin{array}{c}\text { MSN-A } \\
\left(50 \mathrm{mg} \mathrm{kg}^{-1}\right)\end{array}$ & $\begin{array}{c}\text { MSM-A } \\
\left(50 \mathrm{mg} \mathrm{kg}^{-1}\right)\end{array}$ \\
\hline $\mathrm{T}_{\max }(\min )$ & $180,0 \pm 0,0$ & $180,0 \pm 0,0$ \\
$\mathrm{C}_{\max }\left(\mu \mathrm{g} \mathrm{ml}^{-1}\right)$ & $0,0291 \pm 0,0078$ & $0,0105 \pm 0,0016$ \\
$\mathrm{AUC}_{0-6}(\mu \mathrm{g}$. & $9,5931 \pm 1,3731$ & $2,6714 \pm 0,3832$ \\
$\left.\quad \operatorname{min~ml}^{-1}\right)$ & $0,0014 \pm 0,0009$ & $0,0014 \pm 0,0011$ \\
$\mathrm{~K}_{\mathrm{el}}\left(\mathrm{h}^{-1}\right)$ & $719,28 \pm 479,73$ & $785,71 \pm 504,39$ \\
$\mathrm{t}_{1 / 2}(\mathrm{~h})$ & & \\
\hline
\end{tabular}

MSN-A group had the highest solubility at all time points compared to the MSM-A-Cur and free curcumin groups (figure 8). Pharmacokinetic profiles of MSN-A and MSM-A in the bioavailability test after oral delivery can be seen in table 1. MSN-A had a higher maximum curcumin concentration $\left(\mathrm{C}_{\max }\right)$ of $0.0291 \mu \mathrm{g} \mathrm{ml}^{-1}$ in plasma compared to MSM-A $\quad\left(0.0105 \mu \mathrm{g} \mathrm{ml}^{-1}\right)$. Both samples had similar $\mathrm{t}_{\max }=3 \mathrm{~h}\left(\mathrm{t}_{\max }\right.$ is the time at which the maximum concentration is observed). The value of calculated area under the concentration-time curve in the time period of $0-6 \mathrm{~h}\left(\mathrm{AUC}_{0-6}\right)$ for MSN is 3.6 times higher than that of MSM-A. Due to the very low reading of curcumin concentration in the free curcumin group, its $\mathrm{AUC}_{0-6}$ value was not calculated. 
In summary, MSN-A-Cur showed a better release profile, solubility and bioavailabity compared to MSM-A-Cur and free curcumin due to the following distinct benefits: a cubic mesostructure and 3D interconnected pores, a large pore size and reduced diffusion length. These properties together with amine functionalization support a maximum release of curcumin in a sustained manner. The fast release profile of curcumin from MSN-A improved the curcumin dissolution rate and finally increased curcumin bioavailabilty [13].

\section{Conclusions}

A curcumin-amine mesoporous silica nanoparticle composite has been prepared using a simple approach. This approach improved the in vitro solubility of curcumin and, more importantly, the in vivo bioavailability. Our strategy using a mesoporous silica nanoparticle with 3D interconnected large pores as nanocarriers is promising for the development of curcumin oral delivery formulations for future clinical applications.

\section{Acknowledgments}

We acknowledge the support from Ministry of Research, Technology and Higher Education of Indonesia for providing a research grant under the national competition scheme (HIKOM 2016), the Australian National Fabrication Facility and the Australian Microscopy and Microanalysis Research Facility at the Centre for Microscopy and Microanalysis, The University of Queensland.

\section{References}

[1] Anand P, Kunnumakkara A B, Newman R A and Aggarwal B B 2007 Bioavailability of curcumin: problems and promises Mol. Pharma. 4 807-18

[2] Sethi G, Sung B and Aggarwal B B 2009 The role of curcumin in modern medicine Herbal Drugs: Ethnomedicine to Modern Medicine ed K G Ramawat (Berlin: Springer) pp 97-114

[3] Mohanty C and Sahoo S K 2010 The in vitro stability and in vivo pharmacokinetics of curcumin prepared as an aqueous nanoparticulate formulation Biomaterials 31 $6597-611$

[4] Hao N, Jayawardana K W, Chen X and Yan M 2015 One-step synthesis of amine-functionalized hollow mesoporous silica nanoparticles as efficient antibacterial and anticancer materials ACS Appl. Mater. Interfaces 7 1040-5

[5] Fang J H, Lai Y-H, Chiu T-L, Chen Y-Y, Hu S-H and Chen S-Y 2014 Magnetic core-shell nanocapsules with dual-targeting capabilities and co-delivery of multiple drugs to treat brain gliomas Adv. Healthc. Mater. 3 1250-60

[6] Argyo C, Weiss V, Brauchle C and Bein T 2014 Multifunctional mesoporous silica nanoparticles as a universal platform for drug delivery Chem. Mater. 26 435-51

[7] Chen A M, Zhang M, Wei D, Stueber D, Taratula O, Minko T and He H 2009 Co-delivery of doxorubicin and
Bcl-2 siRNA by mesoporous silica nanoparticles enhances the efficacy of chemotherapy in multidrug-resistant cancer cells Small 5 2673-7

[8] Jambhrunkar S, Karmakar S, Popat A, Yu M and Yu C 2014 Mesoporous silica nanoparticles enhance the cytotoxicity of curcumin RSC Adv. 4 709-12

[9] Xia T, Kovochich M, Liong M, Meng H, Kabehie S, George S, Zink J I and Nel A E 2009 Polyethyleneimine coating enhances the cellular uptake of mesoporous silica nanoparticles and allows safe delivery of siRNA and DNA constructs ACS Nano 27 3273-86

[10] Lebold T, Jung C, Michaelis J and Braeuchle C 2009 Nanostructured silica materials as drug-delivery systems for doxorubicin: single molecule and cellular studies Nano Lett. 9 2877-83

[11] Shen D, Yang J, Li X, Zhou L, Zhang R, Li W, Chen L, Wang R, Zhang F and Zhao D 2014 Biphase stratification approach to three-dimensional dendritic biodegradable mesoporous silica nanospheres Nano Lett. 14923

[12] Liu Y et al 2015 Synthesis of mesoporous silica/reduced graphene oxide sandwich-like sheets with enlarged and 'funneling' mesochannels Chem. Mater. 27 5577-86

[13] Zhang Y, Wang J, Bai X, Jiang T, Zhang Q and Wang S 2012 Mesoporous silica nanoparticles for increasing the oral bioavailability and permeation of poorly water soluble drugs Mol. Pharm. 9 505-13

[14] Shen J, He Q, Gao Y, Shi J and Li Y 2011 Mesoporous silica nanoparticles loading doxorubicin reverse multidrug resistance: performance and mechanism Nanoscale 3 4314-22

[15] Ma'mani L, Nikzad S, Kheiri-Manjili H, al-Musawi S, Saeedi M, Askarlou S, Foroumadi A and Shafiee A 2014 Curcumin-loaded guanidine functionalized PEGylated I3ad mesoporous silica nanoparticles KIT-6: practical strategy for the breast cancer therapy Eur. J. Med. Chem. 83 646-54

[16] Datz S, Engelke H, v. Schirnding C, Nguyen L and Bein T 2016 Lipid bilayer-coated curcumin-based mesoporous organosilica nanoparticles for cellular delivery Microporous Mesoporous Mater. 225 371-7

[17] Ahmed A, Hearn J, Abdelmagid W and Zhang H 2012 Dualtuned drug release by nanofibrous scaffolds of chitosan and mesoporous silica microspheres J. Mater. Chem. 22 25027-35

[18] Kim S, Diab R, Joubert O, Canilho N and Pasc A 2016 Coreshell microcapsules of solid lipid nanoparticles and mesoporous silica for enhanced oral delivery of curcumin Colloids Surf. B 140161

[19] Bollu V S, Barui A K, Mondal S K, Prashar S, Fajardo M, Briones D, Rodríguez-Diéguez A, Patra C R and Gómez-Ruiz S 2016 Curcumin-loaded silica-based mesoporous materials: synthesis, characterization and cytotoxic properties against cancer cells Mater. Sci. Eng. C 63393

[20] Zhu M, Zhu Y, Zhang L and Shi J 2013 Preparation of chitosan/mesoporous silica nanoparticle composite hydrogels for sustained co-delivery of biomacromolecules and small chemical drugs Sci. Tech. Adv. Mater. 144

[21] Popat A, Hartono S B, Stahr F, Liu J, Qiao S Z and Lu G Q M 2011 Mesoporous silica nanoparticles for bioadsorption, enzyme immobilisation, and delivery carriers Nanoscale $\mathbf{3}$ 2801-18

[22] Aras A, Khokhar A R, Qureshi M Z, Silva M F, Sobczak-Kupiec A, Pineda E A, Hechenleitner A A and Farooqi A A 2014 Targeting cancer with nano-bullets: curcumin, egcg,resveratrol and quercetin on flying carpets Asian Pac. J. Can. Prev. 15 3865-71

[23] Andersson J, Rosenholm J, Areva S and Lindén M 2004 Influences of material characteristics on ibuprofen drug 
loading and release profiles from ordered micro- and mesoporous silica matrices Chem. Mater. 16 4160-7

[24] Fan J, Yu C, Gao F, Lei J, Tian B, Wang L, Luo Q, Tu B, Zhou W and Zhao D 2003 Cubic mesoporous silica with large controllable entrance sizes and advanced adsorption properties Angew. Chem., Int. Ed. 42 3146-50

[25] Hartono S B, Yu M, Gu W, Yang J, Strounina E, Wang X, Qiao S and Yu C 2014 Synthesis of multi-functional large pore mesoporous silica nanoparticles as gene carriers Nanotechnology 25055701

[26] Hartono S B, Phuoc N T, Yu M, Jia Z, Monteiro M J, Qiao S and Yu C 2014 Functionalized large pore mesoporous silica nanoparticles for gene delivery featuring controlled release and co-delivery J. Mater. Chem. B 2 718-26

[27] Hartono S B, Gu W, Kleitz F, Liu J, He L, Middelberg A P J, Yu C, Lu G Q and Qiao S Z 2012 Poly-l-lysine functionalized large pore cubic mesostructured silica nanoparticles as biocompatible carriers for gene delivery ACS Nano 6 2104-17

[28] Manzano M, Aina V, Aréan C O, Balas F, Cauda V, Colilla M, Delgado M R and Vallet-Regi M 2008 Studies on MCM-41 mesoporous silica for drug delivery: effect of particle morphology and amine functionalization Chem. Eng. J. 137 30-7

[29] Song S W, Hidajat K and Kawi S 2005 Functionalized SBA-15 materials as carriers for controlled drug delivery: influenec of surface properties on matrix-drug interactions Langmuir 21 9568-75

[30] Mitra S P 2008 Stabilizing effect of chitosan on curcumin from the damaging action of alkaline $\mathrm{pH}$ and ultraviolet light J. Surf. Sci. Technol. 24 39-55

[31] Fan J, Yu C, Lei J, Zhang Q, Li T, Tu B, Zhou W and Zhao D 2005 Low-temperature strategy to synthesize highly ordered mesoporous silicas with very large pores J. Am. Chem. Soc. 127 10794-5

[32] Han Y and Ying J Y 2005 Generalized fluorocarbonsurfactant-mediated synthesis of nanoparticles with various mesoporous structures Angew. Chem., Int. Ed. 44 288-92

[33] Suteewong T, Sai H, Bradburry M, Estroff L A, Gruner S M and Wiesner U 2012 Synthesis and formation mechanims of aminated mesoporous silica nanoparticles Chem. Mater. 24 3895-905

[34] Jambhrunkar S, Yu M, Yang J, Zhang J, Shrotri A, Endo-Munoz L, Moreau J, Lu G and Yu C 2013 Stepwise pore size reduction of ordered nanoporous silica materials at angstrom precision J. Am. Chem. Soc. 135 8444-7 